\title{
RESENHA DE MOÇAMBIQUE NO FEMININO: A NARRATIVA DE PAULINA CHIZIANE. SÁVIO ROBERTO FONSECA DE FREITAS (ORG.). JOÃO PESSOA: EDITORA UFPB, 2021
}

Luciana Morais da Silva

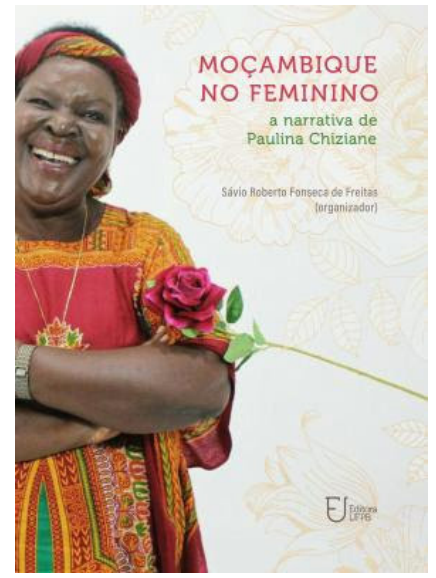

O convite a tratar de uma literatura sobre o feminino e escrita por uma mulher remete ao encontro com um universo por vezes esquecido ou pouco compreendido. A literatura de Paulina Chiziane torna pungente a realidade do feminino em Moçambique, possibilitando a descoberta de sentidos e emoções por vezes obscuros em uma sociedade em que as mulheres aprenderam a ocultar seus gritos e suas dores. Nas palavras da autora: "Reencontrei na escrita o preenchimento do vazio e incompreensão que se erguia à minha volta" 
(CHIZIANE, 2013, p. 202). Não é à toa que Paulina Chiziane tornou-se a primeira mulher a publicar um romance em Moçambique. Sua história de construção literária, bem como sua identidade feminina, permitiu a imersão nas imagens de sua terra e na compreensão dos embates enfrentados pela mulher em uma sociedade profundamente patriarcal.

As narrativas da autora mapeiam o imaginário moçambicano, permitindo que se mergulhe na vastidão de elementos que, conjugados, formam suas personagens femininas e suas lutas quotidianas. Não se trata de um encontro fortuito com estruturas capazes de possibilitar a um autor enveredar pelos caminhos do feminino, e sim uma recuperação atenciosa dos saberes e sabores do ser mulher e escrever sobre mulheres. Como revela a própria autora: "A condição social da mulher inspirou-me e tornou-se meu tema. Coloquei no papel a aspirações da mulher no campo afectivo para que o mundo as veja, as conheça e reflita sobre elas" (CHIZIANE, 2013, p. 202). A escritora tornou-se umas das poucas escritoras de sua terra, principalmente por decidir narrar histórias de mulheres. Suas obras mostram, de certa forma, os gritos emudecidos de mulheres "quando algo Ihes dá amargura da forma como pensam e sentem" (CHIZIANE, 2013, p. 202). 
A escritora moçambicana ao dar voz aos gritos e mesmo censuras, denunciando as dificuldades e a obscuridade em que vivem muitas mulheres, conseguiu realizar um movimento de ressignificação do feminino, não apenas em Moçambique, mas também na diversidade de lugares pelos quais passa. A autora, ao tratar dos preconceitos sofridos, observa: "Como é que a sociedade recebeu a notícia de que eu estava a escrever o meu livro? Primeiro com cepticismo e muito desprezo da parte dos homens" (CHIZIANE, 2013, p. 203). Como muitas de suas narrativas revelam parece que em muitos lugares, ainda hoje, o questionamento é o mesmo: O feminino pode enfrentar seus medos e dores? As mulheres são capazes de narrar suas próprias histórias? E, em sendo capazes de narrar suas histórias, sabem fazê-lo em um romance? Acerca disso, talvez consciente ou não das discussões travadas por Simone de Beauvoir (1949), Chiziane observa seu papel confrontador face ao raciocínio redutor de que cabe à mulher escritora o lugar da desrazão, visto que uma mulher só é capaz de escrever "poeminhas de amor" (CHIZIANE, 2013, p. 203), nada mais. Frente ao conflito diante de sua missão de escrita, ela comprometeu-se a mostrar "pela prática que as mulheres podem escrever e escrever bem" (CHIZIANE, 2013, p. 203). Questionar, propor leituras e, principalmente, demonstrar a importância do feminino para 
as Literaturas de Língua Portuguesa é o objetivo dos autores de Moçambique no feminino: a narrativa de Paulina Chiziane, coletânea crítica organizada por Sávio Roberto Fonseca de Freitas e editada pela UFPB em 2021.

Composta por artigos apresentados como trabalho final da disciplina Literaturas Africanas de Língua Portuguesa e por artigos elaborados por professores que estudam a obra de Paulina Chiziane, o livro organizado por Freitas promove um profícuo debate acerca do feminino e seus enfrentamentos nos caminhos moçambicanos. A conhecida escritora Paulina Chiziane revela-se por uma significativa simplicidade e uma grandiosidade incontornável. A moçambicana não teme o posicionamento firme e a discussão das mazelas sociais. Em seus mundos ficcionais, as personagens são vilipendiadas de seus direitos e de suas vontades, porém ainda assim seguem o caminho da luta, enfrentando os dissabores da mesquinhez humana. Suas lutas são travadas pela força de personagens forjadas pelas imposições da vida quotidiana. A autora nomeia-se como "uma contadora de estórias" (FREITAS, 2021, p. 6), e "é assim que ela apresenta o universo das mulheres moçambicanas para o mundo" (FREITAS, 2021, p. 6), demonstrando a grande relevância delas em suas narrativas (FREITAS, 2021, p. 6). 
O livro é constituído por dez percursos reflexivos diferentes, centrados na produção literária da moçambicana Chiziane e explorando os muitos caminhos presentes em suas obras. Os estudos perpassam a constituição de personagens, seus medos, angústias, memórias, histórias, sofrimentos etc., e surpreendem pelas idas e vindas observadas nas obras ficcionais. A leitura de Ana Oliveira, "A centralidade mística e a fertilidade feminina em Ventos do apocalipse, de Paulina Chiziane", constrói uma reflexão interessante sobre a contradição existente na sociedade moçambicana. Para Oliveira, há um paradoxo na transmissão de histórias: no contexto social a mulher é valorizada, sendo a responsável por passar os ensinamentos da tradição, por meio das narrativas orais; no contexto literário, porém, as mulheres encontraram muita dificuldade para serem reconhecidas por sua produção. A escritora pertence, segundo a análise crítica, a uma geração que tem suas produções literárias marcadas por uma forte herança oral. Assim, a produção de Chiziane teria como ponto central a conquista da valorização no contexto literário, mas também a consolidação de uma forma de narrar muito própria e marcada pelos relatos orais de "histórias de vida" (OLIVEIRA, 2021, p.8). 
Como a pesquisadora observa, a moçambicana revela um conjunto de elementos pertencentes ao feminino, tratando da maternidade, da fecundidade, e ainda destacando os grandes obstáculos impostos à mulher pela convivência em uma sociedade patriarcal, especialmente após a invasão da "cultura do colonizador na sociedade moçambicana" (OLIVEIRA, 2021, p.8). O romance analisado, Ventos do Apocalipse, por exemplo, é apresentado em meio a dualidade entre a miséria da guerra e a existência de uma mulher sedutora e capaz de a tudo conquistar. Nele, a "mulher é tratada como objeto de pertença, entretanto é notório o poder e a força que esta gera no ambiente" (OLIVEIRA, 2021, p. 7). O feminino que sofre e luta contra suas angústias bebe de uma aparente força da terra para, então, transbordar as limitações impostas pela subcondição dada à mulher e redefinir o imaginário local.

A redefinição desse imaginário sobre a mulher em Moçambique também está presente no artigo "Memória e experiência: uma leitura do romance $O$ alegre canto $d a$ perdiz", de Cíntia Kütter. No percurso pelo romance, são encontrados os caminhos da própria mulher moçambicana, tanto o da escritora, quanto o de suas personagens, face aos conflitos presentes na história recente de Moçambique. 
Como destaca Kütter, os testemunhos e experiências nele encontrados propõem o debate de temas polêmicos e, ainda, a exploração da mulher e da terra, perpetuando, em certo sentido, o flagelo: colonizador x colonizado. Assim, a opressão ao feminino, por vezes, é tão violenta que a própria mulher perpetua sua dor com a ideia de que "se fui explorada, irei explorar" (KÜTTER, 2021, p. 23), colocando as filhas como alvos da deturpação do ambiente familiar ao reproduzir "geração após geração, os mandos e desmandos do colonialismo, antes impostos pelo branco colonizador" (KÜTTER, 2021, p. 23).

A memória e a história estão presentes na analise realizada, enfatizando o modo como, mesmo após a independência, os rastros permanecem vivos no imaginário moçambicano e, deste modo, o objetivo da escritora estaria "calcado em estabelecer uma ponte entre o passado desaparecido e a presença do presente, para que este passado colonial, não seja esquecido mesmo após a independência" (KÜTTER, 2021, p. 28, grifos do autor). Nesse mundo aparentemente desencantado, a pesquisadora percebe o silenciamento e o esquecimento como marcos importante para a compreensão do romance, já que são também as memórias, que afetam a personagem 
Maria das Dores, parte da aura sagrada presente na ficção de Chiziane. Como observa Kütter, nesse romance, as personagens femininas e sua trajetória pelas gerações dessa família seriam frutos das memórias doloridas dessa terra mãe.

O percurso empreendido por Débora Pantaleão, em "Tragicidade e loucura: uma análise sobre a trajetória da personagem Emelina no romance 'Ventos do apocalipse' de Paulina Chiziane", esclarece acerca dos caminhos escolhidos para a personagem irromper na narrativa. A proposta de leitura envereda pela loucura e tragédia que perpassam a condição de personagens marcadas pelo caos e pela guerra. À mulher resta certo medo e angústia indicados no desencanto pouco a pouco identificado nas diversas referências ao homem perdido. Nesse contexto, o caminho encontrado para a presente leitura é o da trajetória de loucura e tragicidade presente nos dias da personagem Emelina, a mãe do apocalipse.

Há, portanto, o destaque na narrativa para as feridas abertas pelas dores derivadas das práticas coloniais, marcando profundamente as personagens. Para tanto, "é preciso compreender primeiramente a essência anticolonial do projeto de moçambicanidade do qual ela 
faz parte" (PANTALEÃO, 2021, p. 36). Chiziane em sua produção literária elabora, conforme observado na análise realizada, um mundo de mulheres moçambicanas em meio a um ambiente em que tradição e ruptura se cruzam, estabelecendo confrontos entre tradição e modernidade e, também, entre colonizador e colonizado. Chiziane em sua produção literária promove o debate também acerca das mazelas coloniais perpetuadas pelos próprios colonizados. Acerca disso, Pantaleão observa que a escravidão realizada pelos moçambicanos tem características ainda mais cruéis. Como ela mostra, nos trilhos das reflexões de Mia Couto, as elites africanas foram coniventes com a escravatura, já que enriqueceram, à época, vendendo escravos.

O caráter apocalíptico da personagem feminina evoca uma maneira de romper com expectativas, estabelecendo um novo olhar para o feminino, que levado ao seu limite é capaz de atos impensados e impensáveis. Com isso, o feminino acaba excluído da sociedade, mas profundamente ligado a um mundo de significações, como demonstra a leitura realizada por Pantaleão, em que a loucura e a tragédia perpassam a existência de Emelina.

O estudo realizado por Izabel Teixeira, em "As mulheres e as guerras em Moçambique na obra de Paulina Chiziane", 
ressalva o percurso pela história da construção do país evidenciado pela escritora, principalmente ao expor os "os problemas do colonialismo: exploração, segregação, injustiças" (TEIXEIRA, 2021, p. 58). Nessa trajetória, como o próprio título destaca, há a percepção, em diferentes narrativas, das variadas "questões inerentes à mulher" (TEIXEIRA, 2021, p. 58), ao mesmo tempo em que mostra a denuncia dos problemas do contato entre colonizador $\mathrm{x}$ colonizado, efetuada por Chiziane. Os caminhos escolhidos por Teixeira apontam para o mapeamento da história do país, lembrando apenas das distinções cronológicas entre os romances que não seguem rigorosamente datas ou marcos históricos de modo formal.

Os relatos acerca das experiências das personagens revelam as nuances culturais, as representações identitárias e a imersão na construção do feminino, em meio aos conflitos de guerra, dentre outras questões.

No contexto das mulheres e das guerras, Teixeira conseguiu estabelecer uma leitura panorâmica do cenário desafiador enfrentado pelo feminino face à exploração imposta e aos conflitos históricos e subjetivos. Em suas palavras: "mulher e colônia são uma ambiguidade, antes da guerra, ambas violentamente exploradas, a bel prazer 
e interesse do colonizador, em uma prática de, mais ou menos, meio século de existência" (TEIXEIRA, 2021, p. 69). O feminino em Chiziane, como aponta, em suas diversas ações, vai desenhando a ideia de uma sociedade ampla e variada, especialmente ao descortinar as muitas subjetividades que se conectam.

Larissa Souza, de modo um pouco diferente dos demais, estabelece como proposta refletir sobre duas escritoras contemporâneas, Paulina Chiziane e Lília Momplé, em "A autoria feminina em moçambique pós 75: algumas reflexões". A reflexão tem como foco inicial o mapeamento das lutas do feminino pelo direito de estudar, a educação, segundo ela, é "muito pouco discutida nos estudos sobre a produção de mulheres" (SOUZA, 2021, p. 72), apesar de ser essencial para que se compreenda a invisibilidade e os preconceitos "que rondam o espaço crítico sobre o feminino" (SOUZA, 2021, p. 72). O resultado do acesso à educação apenas a grupos privilegiados acaba por perpetuar preconceitos e consolidar a estapafúrdia ideia de que falta à mulher capacidade, como já denunciado por Chiziane (2013) em diferentes momentos.

Com trajetórias distintas, mas marcadas pelo enfrentamento das mazelas de seu país, Chiziane e 
Momplé lançam mão do feminino para explicitá-las. Em seu estudo, Souza mostra a origem e a história das escritoras, lembrando que o enfrentamento das problemáticas sociais realizado pelas escritoras culmina na tessitura de uma força de resistência diante das complicações que envolvem o feminino em Moçambique. Ela aproveita e traça o panorama das publicações no contexto brasileiro, refletindo o modo como as escritoras acabam preteridas frente aos escritores, e afirma: "A marginalização da autoria feminina pela crítica e, consequentemente, pelo mercado editorial não é apenas um problema em Moçambique" (SOUZA, 2021, p. 81). Assim, notase a complexidade enfrentada por cada uma das duas escritoras para conseguir publicar e conquistar o espaço na literatura.

No artigo "Aspectos simbólicos e místicos da subida ao monte em $O$ sétimo juramento", Maria Graciele de Lima apresenta os diferentes percursos que cada personagem seguirá de acordo com aquilo que desejam, que buscam, lembrando ainda a presença da tradição oral na narrativa de Chiziane. A experiência das personagens revela, assim, um diálogo com os símbolos construídos e alicerçados na oralidade, uma vez que suas vivências são pouco a pouco 
desvendadas a partir de uma apreensão de seu caráter simbólico. Para ela, "são várias as simbologias encontradas. Entre elas, a água, o fogo, a serpente, ou locais como caverna, casa e monte" (LIMA, 2021, p. 99).

As reflexões apresentadas no estudo destacam a importância desses símbolos para a elaboração da obra, e o modo como sua apreciação contribui para ampliar a compreensão sobre o romance. Nessa sequência, Lima afirma ser "indispensável elucidar o papel simbólico desempenhado pela subida ao monte vivida por Vera e David" (LIMA, 2021, p. 105), pois como vai demonstrando a "solidão de um monte" já foi, por vezes, refúgio de profetas e eremitas em busca "de encontrar respostas" ( $p$. 106). Ao lado da subida ao monte, sua análise enveredase também pela experiência mística, percebendo-os como pilares, junto à tradição oral, a serem considerados para a compreensão da obra. A busca pelos aspectos simbólicos e místicos presentes em $O$ sétimo juramento culmina, por exemplo, na conclusão de que a obra "possui marcas da história de uma sociedade" (LIMA, 2021, p. 107) e, por isso, se constitui por uma maneira própria "de simbolizar conceitos, experiências, valores" (p. 107).

Marlon Barbosa, ao debruçar-se sobre o romance Balada de amor ao vento, produz uma interessante 
percepção acerca de dois elementos chaves para sua proposta: a história e a mulher. Seu estudo "A filosofia da balada: violência, sintoma e deportação. Uma leitura de Balada de amor ao vento, de Paulina Chiziane" estabelece a história como um corpo ferido e desenvolvido por meio do poder, da possibilidade de narrar, e, nesse contexto, a mulher, a própria autora, contribuiu para consolidar uma nova tradição, especialmente ao lutar por seu direito de escrever e "desafiar todas as vozes que se auto intitulam detentoras da verdade e únicas aptas a contar histórias" (BARBOSA, 2021, p. 109). A capacidade de narrar a história é, também, apresentada na voz da narradora que, ao colocar frente a frente tradição e modernidade, estabelece sua categoria de voz da experiência para questionar e denunciar "a condição feminina, o casamento, a poligamia, a submissão da mulher" (BARBOSA, 2021, p. 111) e outros temas, em um "complexo duelo invisível entre o velho e o novo" (BARBOSA, 2021, p. 111).

Sendo assim, em suas reflexões, Barbosa aponta a proposta da escritora de "repensar a história e a cultura de seu país (sic) por meio da literatura" (BARBOSA, 2021, p. 113), tramando a ficcionalização da própria vida ao trazer "à tona o mal de uma nação ferida, a história não contada de um corpo ferido" (BARBOSA, 2021, p. 113). Nesse universo 
literário configurado por Chiziane, é possível perceber como a escritora, atenta às influências de outras culturas e da contemporaneidade, produz em seus romances conexões entre memória e cultura local, construindo dispositivos de discussão acerca do passado colonial e das relações estabelecidas entre colonizador e colonizado, como também formulando maneiras de transcendência e de superação. Como diz Barbosa, na escrita de Chiziane: "há um jogo de deslocamento tão intenso na construção do romance que a imagens, por vezes, puramente, poéticas ultrapassam a poesia e transformam-se em crítica severa a realidade" (BARBOSA, 2021, p. 113).

Norma Lima empreende um percurso entre as literaturas brasileira e moçambicana, buscando a comparação entre duas autoras, do mesmo modo que Larissa Souza o faz, porém, com o diferencial de serem escritoras de países e continentes distintos. Sua leitura em "Úrsula e $O$ alegre canto da perdiz: quando as águas se encontram em Maria Firmina do Reis e Paulina Chiziane", permite observar a importância das duas escritoras para o imaginário nacional brasileiro e moçambicano, principalmente pelo caráter pioneiro da conquista realizada por cada uma das escritoras em seus respectivos países. Como revela, "a afirmação de 
posições contra-ideológicas por parte dessas escritoras" acabou colaborando, "nos diferentes contextos em que atuaram, para a construção de novos valores no terrenos das mentalidades" (LIMA, 2021, p. 119).

A professora ressalva a essencialidade da escrita feminina em momentos de singular exceção, especialmente quando realizam o feito de conquistar e consolidar seu lugar como escritoras. Afinal, as lutas travadas por Chiziane e Reis não são exclusivas de seus contextos históricos, ainda que apresentem suas peculiaridades, visto que por muitos anos as mulheres serviram apenas para serem leitoras/ ouvintes ou personagens de textos de autoria masculina.

A pesquisadora brasileira, que de modo recorrente coloca em diálogo as literaturas brasileira e moçambicana, produz uma interessante relação entre as duas autoras, promovendo uma reflexão acerca do subespaço dedicado ao feminino e, ainda, a subserviência destinada ao feminino. Seu percurso teórico apropria-se dos sentidos em torno da fragilidade e incapacidade imposta à mulher apenas por sua sexualidade e não por seu conhecimento e capacidade de escrita.

Em "A balada em prosa poética de Paulina Chiziane", Sávio Freitas, o organizador do presente conjunto de textos 
críticos, demonstra sua envergadura para tratar da literatura poética escrita pela moçambicana. Segundo ele, a "forma literária (a balada em prosa poética)" (FREITAS, 2021, p. 135), em Chiziane, estaria "em harmonia com o conteúdo (a estória de amor)" (FREITAS, 2021, p.135), demonstrando a configuração do lirismo poético na prosa, com o intuito de levar para o texto escrito elementos estéticos da tradição oral de contação de histórias em torno da fogueira. Como o professor destaca: “O fogo é o elemento que vem aquecer os fatos e os afetos narrados por Sarnau [...]. A luz das chamas representa a memória dos contadores de estórias que, como Sarnau, utilizam-se desta tradição por amor e compromisso com a cultura local" (FREITAS, 2021, p. 144). Pensar a narrativa de Chiziane a partir de sua tradição oral coloca em destaque a sensibilidade da escritora ao tratar da narração oral apreendida em casa, com sua avó (CHABAL, 1994, p. 292-301), como também enfatiza uma das características mais marcantes da Literatura em Moçambique, que é a capacidade de transmutar a escrita, produzindo uma prosa com traço lírico.

Nesse sentido, nota-se a complexidade presente na obra investigada por Freitas, afinal, em Balada de amor ao vento, Chiziane coloca em diálogo narrativas de encaixe 
e forja a força do amor, também presente em outros romances. Como ressalva Freitas, o amor não é capaz de garantir o poder de escolha para o feminino, contudo, a busca da mulher parece premiada por uma boa união. $\mathrm{Na}$ construção narrativa da moçambicana, as relações humanas demonstram-se carregadas por conflitos e desgastes, haja vista à complexidade presente no percurso feminino, mas, ao fim, o amor acaba reunindo corações. Em suas histórias, ela produz imagens poéticas, com acentuada emotividade, que, em meio a tempestades, transformam-se em duras críticas à realidade. Como destaca Freitas, as vozes se cruzam, pois estão ligadas "pelo amor tão avassalador como a força do vento" (FREITAS, 2021, p. 152).

Zuleide Duarte e Izabel Martins, em "O jogo e o jugo: entre o pós-colonial e a magia em $O$ sétimo juramento", empreendem um interessante percurso pela obra de Paulina Chiziane, apontando a importância dela no imaginário moçambicano. O percurso de leitura usado pelas autoras é construído a partir de um levantamento bastante frutífero das produções literárias dos últimos tempos, buscando interpretar, de certo modo, "a temática da colonização mental e seus desdobramentos" (DUARTE; MARTINS, 2021, p. 154), demonstrando as profundas lacerações reproduzidas 
mesmo após a independência. A perpetuação da arrogância e das feridas vertidas no quotidiano dos Moçambicanos permaneceu, "fazendo emergirem novos chefes, tiranos e exploradores do povo" (DUARTE; MARTINS, 2021, p. 154).

O colonialismo, conforme foram demonstrando as pesquisadoras, gerou marcas profundas e transformou o desejo dos colonizados que, ao necessitarem se converter aos costumes do colonizador, acabaram por "assimilar" também o desprezo pelos seus irmãos da terra. O ódio e a ganância, presente no mapa da colonização, são também elementos constantes na escrita de Chiziane que narra as profundezas da agonia vivida por homens e mulheres de Moçambique. A leitura crítica das pesquisadoras aponta para uma busca de manutenção de poder perpetrada pelos novos chefes e, assim, a imersão na corrupção como geradora de novas desgraças, isto é, o desdobramento da colonização mental. Como demonstram há a recorrência da "questão do bem e do mal" (DUARTE; MARTINS, 2021, p. 154), denunciando a perversidade presente nas personagens. As promessas de melhoria e de qualidade de vida para o povo deram lugar à manutenção da desigualdade, como vai sendo mostrado na leitura realizada da obra $O$ sétimo juramento, de Paulina Chiziane. Nesse estudo, anota-se inclusive o retorno às 
práticas ligadas aos cultos de possessão, banidos à época da colonização, pois, apesar de negados por anos, face ao menor problema as personagens lançam mão da magia da terra para conseguir consolidar sua vontade.

A passagem do protagonismo da ação para o protagonismo na autoria aparece, portanto, como um marco a ser celebrado, conforme foi sendo destacado nas diferentes leituras dispostas na presente coletânea crítica. O movimento de mudança engendrado no conjunto das obras da autora promove um fortuito percurso pelo corpo feminino olhado por si mesmo, permitindo um mergulho nos universos femininos representados na literatura. Chiziane ao enveredar pela resistência do corpo, talvez a única capaz de quebrar as barreiras patriarcais, fundamenta a ideia de uma mulher sábia e capacitada a resistir com a plena compreensão acerca de sua sexualidade, não frágil, mas matriarcal. O olhar pautado na sabedoria da oralidade e, ainda, marcado pelo reconhecimento dessa força da mulher remete ao contínuo processo perpetrado pelo feminino para extinguir a ideia de incapacidade de aprender ou de ter domínio sobre sua própria vida. A confecção dessa prosa poética que, por sua vez, se alicerça em um saber passado de geração para geração remete a muitos dos percursos encontrados em Ana Mafalda Leite. 
A luta narrada por Chiziane e minuciosamente descrita em suas obras de ficção acaba por dialogar com o enfrentamento presente em Beauvoir.

A pluralidade de abordagens que observamos entre os artigos que compõem Moçambique no feminino: a narrativa de Paulina Chiziane, resultante de uma disciplina ministrada no decorrer do projeto de pesquisa com o mesmo título, organizado pelo Prof. Dr. Sávio de Freitas e editado pela UFPB em 2021, não apenas demonstra o atual estado de vitalidade que envolve os estudos relacionados ao feminino e às Literaturas de Língua Portuguesa, como também permite observar em todos os autores envolvidos na publicação o interessante entrelaçamento em relação aos conceitos em torno da obra da escritora moçambicana Paulina Chiziane, mas também o criativo olhar crítico voltado especificamente para diferentes perspectivas acerca das obras estudadas em cada ensaio.

Os artigos têm como linha mestra a observação do feminino nas obras da escritora que vem despertando ou renovando o debate acerca da presença do feminino na literatura e sua grande importância, principalmente em espaços onde a voz da mulher tende a desaparecer. Por muito tempo, segundo as tradições clássicas, a literatura 
se pautou, também em Moçambique, na interdição do discurso feminino, apostando somente na literatura escrita por homens e brancos. É verdade que algumas escritoras conseguiram ganhar destaque, porém essa transmutação demorou inúmeros anos e foi conquistada após muita luta e conflito. Paulina Chiziane, por exemplo, passou por inúmeros percalços como destaca em diversas entrevistas, ponderando a dificuldade encontrada para escrever e, depois, para ser lida.

Afinal, em um país de grandes disparidades e outrora colônia, o ser humano já sofre com o preconceito dominador x dominado, além dele, há para a mulher o obscurantismo da distinção sexual. Como ressalva a escritora: "Nós, mulheres, somos oprimidas pela condição humana do nosso sexo, pelo meio social, pelas idéias fatalistas que regem as áreas mais conservadoras da sociedade" (CHIZIANE, 2013, p. 203). Há, portanto, no olhar para o feminino uma fatalidade calcada na perspectiva patriarcal de que a mulher é hierarquicamente inferior ao homem. Trata-se, assim, a mulher como um objeto comprável, controlável e, obviamente, descartável. A voz de Chiziane, como foi possível observar nas leituras realizadas, invalida completamente os fundamentos dos discursos de inferiorização do feminino, capacitando a mulher a existir, a 
conquistar, a resistir. A guerra perpassa seus mundos, indicando que as lacerações deixadas pelo passado colonial ainda reverberam no quotidiano de Moçambique, porém a autora alude a possibilidade de transcender por meio da esperança.

\section{REFERÊNCIAS}

BEAUVOIR, Simone de. Le deuxième sexe: L'expérience vécue, II. Paris: Éditions Gallimard, 1949.

CHABAL, Patrick. Paulina Chiziane. In: Vozes moçambicanas: literatura e nacionalidade. Lisboa: Veja, p. 292-301, 1994.

CHIZIANE, Paulina. Eu, Mulher... por uma nova visão do mundo. In: Revista Abril - Revista do Núcleo de Estudos de Literatura Portuguesa e Africana da UFF, Vol. 5, n. 10, p. 199-205 abril de 2013. Disponível em: https://periodicos.uff.br/revistaabril/article/view/29695/17236. Acesso em: 12 fev. 2021.

FREITAS, Sávio Roberto Fonseca de (Org.). Moçambique no feminino: a narrativa de Paulina Chiziane. João Pessoa: Editora UFPB, 2021.

LEITE, Ana Mafalda. Oralidades e escritas pós-coloniais: estudos sobre literaturas africanas. Rio de Janeiro: EdUERJ, 2012.

\section{Luciana Morais da Silva}

Pós-Doutora em Letras - Estudos de Literatura -Teoria da Literatura e Literatura Comparada - pela Universidade do Estado do Rio de Janeiro (2018).

Atua como professora/tutora da Faculdade Unyleya. Trabalha também com consultoria acadêmica e revisão.

Participa do Grupo de Pesquisa do CNPq “Nós do Insólito: vertentes da ficção, da teoria e da crítica".

Lattes: http://lattes.cnpq.br/2847441618182578

E-mail: lulu_msilva@yahoo.com.br

ORCID iD: https://orcid.org/0000-0001-7757-801X 